See discussions, stats, and author profiles for this publication at: https://www.researchgate.net/publication/334303984

\title{
Efficiency Investigation of A Protection and Correction Solid State Device for Low-Voltage Distribution Networks
}

Conference Paper · July 2019

DOI: 10.1109/UPEC.2019.8893523

CITATIONS

READS

0

52

4 authors, including:

Stelios Ioannou

UCLan Cyprus

22 PUBLICATIONS 45 CITATIONS

SEE PROFILE

M. Darwish

Brunel University London

109 PUBLICATIONS 1,148 CITATIONS

SEE PROFILE

Ghanim Putrus

Northumbria University

118 PUBLICATIONS 1,346 CITATIONS

SEE PROFILE

Some of the authors of this publication are also working on these related projects:

ERON: Autonomous Surface Vessel View project

Project Power Quality Issues associated with Transients and Lightning View project 


\section{Efficiency Investigation of A Protection and Correction Solid State Device for Low-Voltage Distribution Networks}

\author{
S. Ioannou \\ Department of Electrical and \\ Electronic Engineering \\ School of Sciences \\ University of Central Lancashire \\ Pyla, Larnaca, Cyprus \\ SIoannou2@uclan.ac.uk
}

\author{
CC Marouchos \\ Department of Electrical \\ Engineering, Computer \\ Engineering and Informatics \\ Cyprus University of Technology \\ Limassol, Cyprus \\ christos.marouchos@cut.ac.cy
}

\author{
M. Darwish \\ School of Engineering and Design \\ Brunel University \\ London, UK \\ mohameddarwish@brunel.ac.uk
}

\author{
G. A. Putrus \\ Department of Mathematics \\ Physics and Electrical \\ Engineering \\ Northumbria University, \\ Newcastle, U.K \\ ghanim.putrus@unn.ac.uk
}

\begin{abstract}
A Solid State device which can limit and interrupt a fault, apply power factor correction and voltage regulation under normal conditions is presented with an investigation of its efficiency. The losses of the switching semiconductors are investigated by employing the PSIM Thermal Module. This work closely investigates the phase shift between the current and voltage waveforms for a $50 \mathrm{~Hz}$ system and switching frequency of $5 \mathrm{kHz}$ before modelling and calculating the IGBT losses. For DC/DC converters the associated currents and voltages are in phase. However, as this work shows for switched capacitor circuits there is a $90^{\circ}$ phase shift between current and voltage. Finally, calculated losses are compared to simulated losses as well as to other methodologies suggested in literature.
\end{abstract}

Keywords - Efficiency, Losses, Thermal Module, Fault Limiting, Switched Capacitor, Power Factor.

\section{INTRODUCTION}

The switched capacitor circuit [1] - [9] which is inserted in series with the line, Fig. 1 enables a number of functions to be performed that enhances power quality [10]. During normal operation the power factor is improved. In the event of a fault, the fault current is limited to safe levels and interruption is possible. The new feature which is presented in this paper is the correction of Voltage sags. Correction up to $14 \%$ is demonstrated with a certain set of $\mathrm{L}$ and $\mathrm{C}$ values. The efficiency of such a device inserted in the main flow of power in a Low Voltage Distribution Network is of paramount importance. The losses are identified in the switching semiconductor devices and the transformer.

The industry of power electronics and switched mode power supplies has been revolutionized by the introduction of semiconductor switches. Since, the introduction of transistors (bipolar and field effect) engineers and scientists are pushing the innovation envelope, producing products with higher durability and efficiency [11]-[13]. Metal Oxide Semiconductor Field Effect Transistor (MOSFET) and Insulated Gate Bipolar Transistors (IGBT) have dominated the designs of switched mode power supplies [14], [15]. IGBT offer higher operating voltages than MOSFET. On the other hand MOSFET are cheaper and also offer higher switching speeds as compared to IGBT. As indicated by the data tabulated on Tables I and II, MOSFET offer much lower switching delays as compere to IGBT. The data of Tables I and II have been obtained or derived directly from the device datasheet [16]-[20].

Another very important selection criterion includes the losses of semiconductor devices which are divided into switching and conduction. As explained and analyzed in [21] and [22] the conduction losses of MOSFET are proportional to the on-resistance $\left(R_{D S(o n)}\right)$ and drain current $\left(I_{D}\right)$, whereas in the case of IGBT are proportional to the collector-emitter saturation voltage $\left(\mathrm{V}_{\mathrm{CE}(\mathrm{SAT})}\right)$ and collector current $\left(\mathrm{I}_{\mathrm{C}}\right)$. The switching losses for both cases are proportional to the switching frequency.

For DC/DC converters the associated currents and voltages are in phase. However, as this work shows for switched capacitor circuits there is a $90^{\circ}$ phase shift between current and voltage. Therefore, this work closely investigates the phase shift between the current and voltage waveforms for a $50 \mathrm{~Hz}$ system and switching frequency of $5 \mathrm{kHz}$ before modeling and calculating the IGBT losses.

\section{THE OPERATION OF THE PROPOSED DEVICE}

In this section the four functions of the circuit Fig.1 are presented. As shown in Fig. 1, the Switched Capacitor (SC) circuit is inserted in series with the load. By proper action of the two switches this circuit can limit the current in the event of a fault, improve the power factor in normal operation and correct to some extent voltage sags.

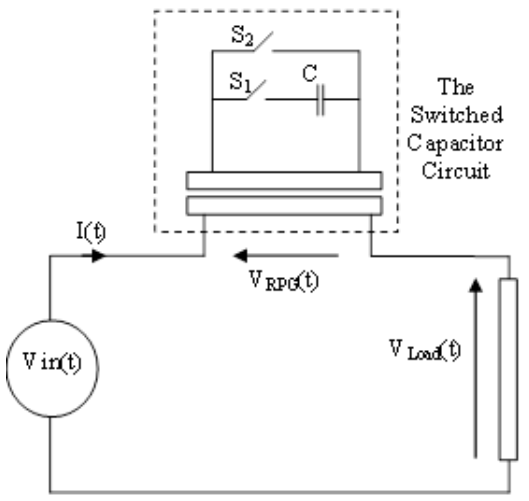

Fig.1: The Switched Capacitor Circuit.

PRE-PRINT: S. Ioannou, CC Marouchos, M. Darwish and G. A. Putrus, "Efficiency Investigation of A Protection and Correction Solid State Device for LowVoltage Distribution Networks", 54 ${ }^{\text {th }}$ International Universities Power Engineering Conference (UPEC19), 978-1-7281-3349-2/19/\$31.00 @2019 IEEE, Romania, 2019. 


\section{A. FAULT LIMITING AND INTERRUPPTION}

This function of the circuit is well explained in [1]-[9]. In the event of a fault the impedance of the SC circuit is increased accordingly by setting the duty cycle (D) of the switches. This impedance is reflected through the transformer to the line thus the current is limited to a safe value.

\section{B. POWER FACTOR CORRECTION}

The impedance of the SC circuit is set capacitive during the normal operation of the Low Voltage Network by setting the appropriate duty cycle of the switches. It was shown [1] that the power factor can be improved from 0.786 to 0.85 . This is done with reference to Fig.2. For every value of the power factor PF, there is a corresponding value for the load voltage and the voltage across the semiconductor switches and the passive components of the switched capacitor, $\mathrm{V}_{\mathrm{SC}}$. From Fig. 2 , D is found for the desired power factor. It is found from this graph that for power factor corrected to 0.85 lagging, the load voltage is always $5 \%$ higher than the supply.

\section{Voltage SAG CORRECTION}

This is a new feature and it is taking advantage of the fact that the load voltage is increased with the insertion of the SC circuit, Fig. 2. As it was shown above, a compromise is achieved between power factor and acceptable increase of load voltage at $\mathrm{D}=0.535$ improving the power factor to 0.85 and allowing an increase of the load voltage of only $5 \%$. This "disadvantage" of the SC circuit is turned into an advantage when there is a sag in the mains voltage at the point of connection. As indicated in Fig. 2 it is possible to set the load voltage at about $12.5 \%$ higher with reference to the nominal voltage at the point of connection. The value of $\mathrm{D}$ is close to 1as read from Fig.2. Sag voltage correction is demonstrated in Fig. 3 where a sag of $15.3 \%$ is corrected back to $236.9 \mathrm{~V}$, which is only $2.05 \%$ from its value before the disturbance.

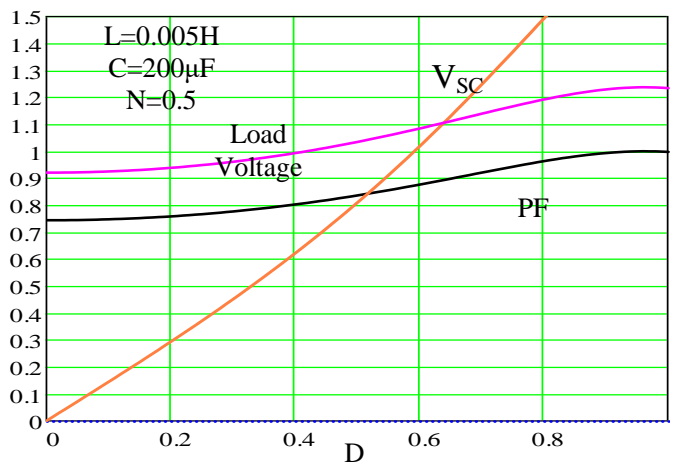

Fig.2: Power Factor and Circuit Voltages against the Duty Cycle of the Switches D.

\section{CALCULATION OF LOSSES}

\section{A. CURRENT Voltages of THE SEMICONDUCTOR SWITCHES}

In order to derive the losses in the transistors the voltage across them and currents through them must be established.
The duty cycle D of the switch $\mathrm{S}_{1}$ the SC circuit in Fig.1 is such that the current is leading the supply voltage therefore the capacitor voltage is lagging the current by $90^{\circ}$. The modes of the SC circuit are shown in Fig.4 (a) and (b). It is shown that the voltage across switch $S_{1}$ is the capacitor voltage reversed and the voltage across switch $\mathrm{S}_{2}$ is the capacitor voltage. The ideal bidirectional switches of Fig.1 are implemented by two IGBTS connected as shown in Fig.4 (c).

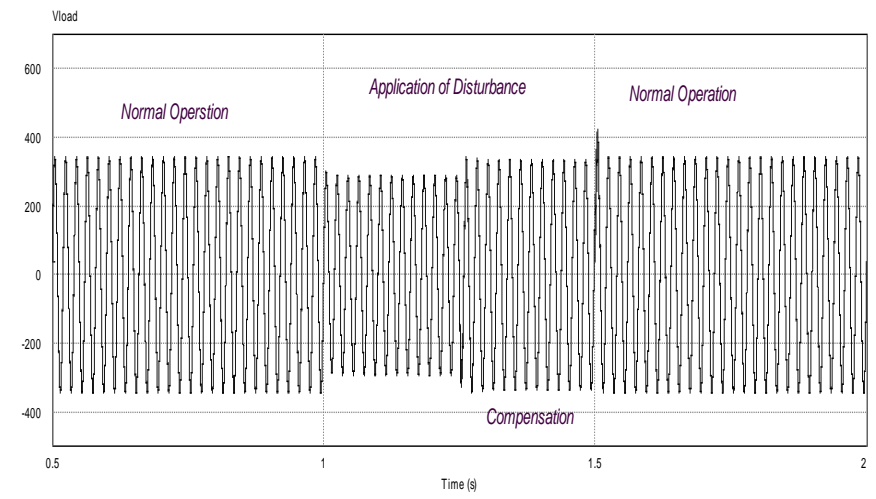

Fig.3: Voltage at the Connection Point.

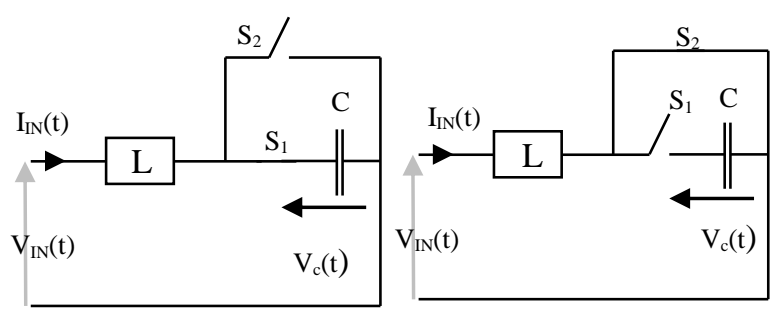

(a)

(b)
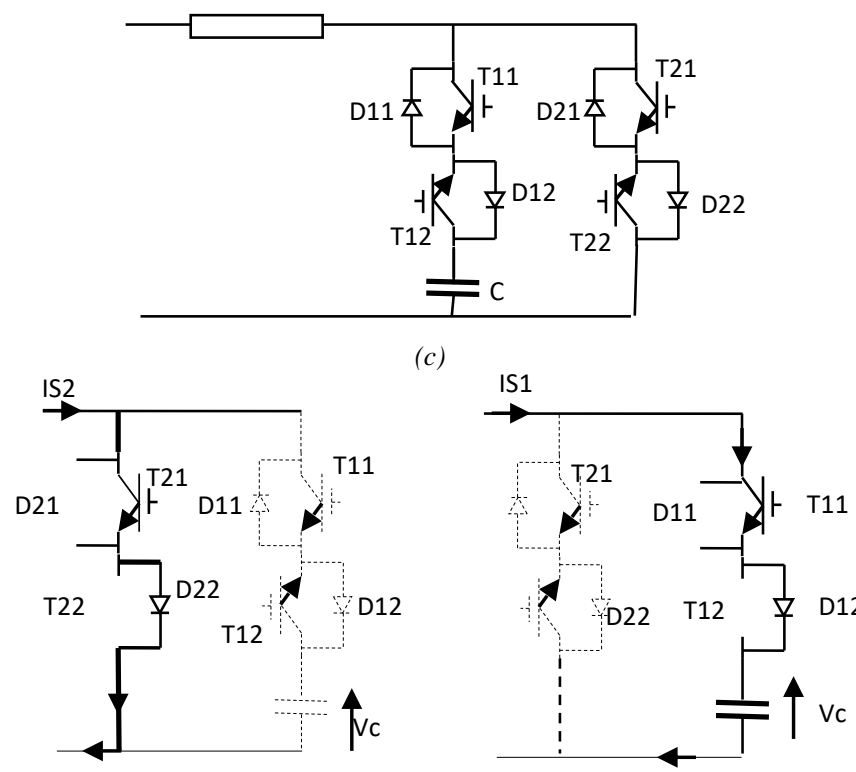

(d) Mode A

(e) Mode B

Fig.4: (a) and (b) Modes of the SC circuit (c) Implementation of the ideal switch $\mathrm{S}_{1}$ with bidirectional (d) Mode $\mathrm{A}$ and Mode $\mathrm{B}$ of the implemented circuit.

PRE-PRINT: S. Ioannou, CC Marouchos, M. Darwish and G. A. Putrus, "Efficiency Investigation of A Protection and Correction Solid State Device for Low-

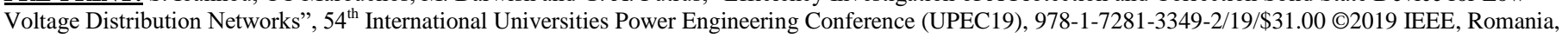
2019. 
The current in each branch of Fig.4 (c) can flow in both directions. In the branch with the capacitor, S1 is implemented with two IGBTs, T11 and T12. Each transistor has the usual anti-parallel diode. The current for S1, IS1 flows through T11 and D12 in one direction and through T12 and D11 in the opposite direction. In a similar way the current flows in the other branch.

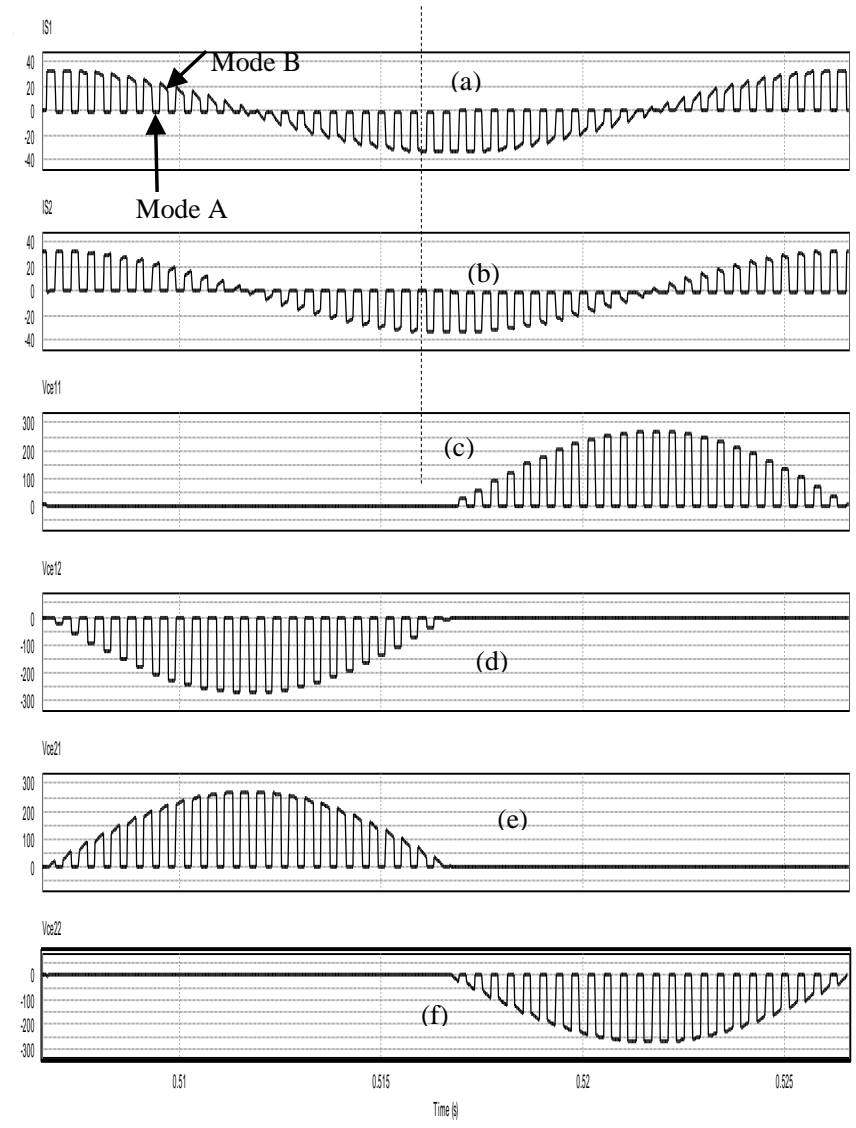

Fig. 5: Voltage Across and Current through the transistors

(a) Current through S1, (b) current through S2, (c) Voltage across transistor T11, (d) Voltage across transistor T12, (e) Voltage across transistor T21, (f) Voltage across transistor T22.

The chopped waveforms of voltages across the transistors and currents through them of circuit Fig.4a are shown in Fig.5. The modes of the circuit are increased to four (ABCD) with the implementation of S1 and S2 with IGBTs. Modes A and B are shown in Fig. 4 (d) and (e) only. In Mode A the current is positive; it flows downwards through T21, D22. The capacitor voltage appears across the non-conducting transistors in the other branch T11 and T12, +ve at Collector of T12 and -ve at cathode of D11 Fig. 4 (d). D11 is forward biased even though not conducting hence the voltage across it is practically zero, same with T11. The capacitor voltage therefore appears across T12, reversed, Fig.5.(d). Note that the current is a chopped cosine waveform Fig.5 (b). During this mode A the losses are the conduction losses in D21 and T22.
In Mode B Fig.4e the current is positive; it flows downwards through T11, D12. The capacitor voltage appears across the non-conducting transistors in the other branch T22 and T21, +ve at Collector of T21 and -ve at cathode of D22 Fig.4 (e). D22 is forward biased even though not conducting hence the voltage across it is practically zero, same T21. During this mode B the losses are the conduction losses in D12 and T11

Switching losses take place when one mode is replaced by the next one. Modes A and B are interchanged (A B A B ...) during the Positive current half-cycle and Modes $C$ and $D$ are interchanged (C D C D...) during the Negative current halfcycle. Within one cycle of the switching frequency there are two mode changes e.g from mode A to mode B and back to mode A, Fig.5. For each change of mode a transistor and a diode are switching $\mathrm{OFF}$ and another transistor and a diode switching ON, two switching losses. From mode A to Mode B transistor T21and diode D22 are switching OFF and transistor T11 and a diode D12 switching ON. Since this process is repeated within one switching frequency cycle, the total switching losses within a cycle of the switching frequency is four times the losses of one transistor. Note that the losses in the reverse-connected diodes are neglected because according to the IGBT datasheets as shown on Tables I these free-wheel diodes offer superfast recovery; few ns instead of hundreds ns.

More specifically in the transition from A to B, T21 and D22 are switching OFF from a current given by $I_{p} \cos (\omega n T)$ and the voltage across them is raised to $V_{m} \sin (\omega n T)$ across them in $t_{\text {Fall }}$ (ns). Because D22 is forward biased in mode B the voltage across it is practically zero for switching losses and this voltage appears across T21, Fig. 5 (e) (reversed but no problem!). At the same time T11 and D12 are switching ON from zero to a current $I_{p} \cos (\omega n T)$ and the voltage is dropping from $V_{m} \sin (\omega n T)$ to zero in $\mathrm{t}_{\text {Rise }}(\mathrm{ns})$, Fig.5 (c)

Therefore for each change of mode we have a transistor and a diode switching OFF and another transistor and a diode switching ON, two switching losses.

\section{B. Losses DURING Normal OPERATION, No DisturbanCE}

The use of the thermal module of PSIM to study the losses of semiconductor devices has been investigated by [23] whereas [1] derived the theoretical losses of IGBT. This work will investigate and compare the PSIM simulated results and the theoretical of IGBT-IXGT40N60C2D1 which is available in the PSIM Thermal Module Database.

TABLE I: IGBT CHARACTERISTICS at $25^{\circ} \mathrm{C}$
\begin{tabular}{|c|c|c|c|c|c|c|}
\hline \multirow{2}{*}{ Model } & $\mathrm{I}_{\mathrm{C}}$ & $\mathrm{V}_{\mathrm{CE}(\mathrm{sat})}$ & \multicolumn{2}{|c|}{$\begin{array}{c}\text { Delay } \\
(\mathrm{ns})\end{array}$} & \multicolumn{2}{c|}{$\begin{array}{c}\text { Rise } / \text { Fall } \\
(\mathrm{ns})\end{array}$} \\
\cline { 5 - 8 } & $(\mathrm{A})$ & $(\mathrm{V})$ & $\mathrm{t}_{\mathrm{d}(\mathrm{on})}$ & $\mathrm{t}_{\mathrm{d}(\mathrm{off})}$ & $\mathrm{t}_{\text {Rise }}$ & $\mathrm{t}_{\text {Fall }}$ \\
\hline IXGT40N60C2D1 & 75 & 2.6 & 18 & 90 & 20 & 32 \\
\hline CM1000HA-24H & 1000 & 3.6 & 600 & 1200 & 1500 & 350 \\
\hline F3L300R12PT4 & 460 & 2.15 & 210 & 380 & 90 & 70 \\
\hline FF450R12KE4 & 520 & 2.15 & 200 & 500 & 45 & 10 \\
\hline IRGPS60B120KDP & 105 & 2.5 & 72 & 366 & 32 & 45 \\
\hline
\end{tabular}


TABLE II: MOSFET CHARACTERISTICS at $25^{\circ} \mathrm{C}$

\begin{tabular}{|c|c|c|c|c|c|c|c|}
\hline \multirow{2}{*}{ Model } & \multirow{2}{*}{$\begin{array}{l}\mathrm{V}_{\text {DSBV }} \\
(\mathrm{V})\end{array}$} & \multirow{2}{*}{$\begin{array}{c}\mathrm{R}_{\mathrm{DS}(\mathrm{ON})} \\
(\mathrm{m} \Omega)\end{array}$} & \multirow{2}{*}{$\begin{array}{l}\mathrm{I}_{\mathrm{D}} \\
(\mathrm{A})\end{array}$} & \multicolumn{2}{|c|}{$\begin{array}{c}\text { Delay } \\
(\mathrm{ns})\end{array}$} & \multicolumn{2}{c|}{$\begin{array}{c}\text { Rise } / \text { Fall } \\
(\mathrm{ns})\end{array}$} \\
\cline { 5 - 9 } & & & & $\mathrm{t}_{\mathrm{d}(\text { on })}$ & $\mathrm{t}_{\mathrm{d}(\mathrm{off})}$ & $\mathrm{t}_{\text {Rise }}$ & $\mathrm{t}_{\text {Fall }}$ \\
\hline STW45NM50 & 500 & 70 & 45 & 27 & 22 & 108 & 88 \\
\hline SCT30N120 & 1200 & 90 & 45 & 19 & 45 & 28 & 20 \\
\hline IRF3805 & 55 & 3.3 & 75 & 20 & 87 & 150 & 93 \\
\hline GS66516 & 650 & 25 & 60 & 4.6 & 14.9 & 12.4 & 22 \\
\hline
\end{tabular}

As shown on Tables I and II, state of the art IGBT can handle much higher currents than MOSFET at the expense of much higher delays. Hence, MOSFET are the preferred choice for high switching applications.

Fig. 6 is the implementation of a bidirectional switch by two transistors $T_{1}$ and $T_{2}$ using the PSIM Thermal Module. This configuration replaces $\mathrm{S} 1$ and $\mathrm{S} 2$ in Fig.4 (a)and (b). This configuration includes the thermal resistances of the transistor and the diode, and the sum of the thermal resistances between the junction to case $\left(R_{t h-j c}\right)$, the case and heat sink $\left(R_{t h-c s}\right)$, and between the heat sink and the ambient $\left(R_{\text {heatsink }}\right)$. The ammeters represent the conduction and switching losses in watts.

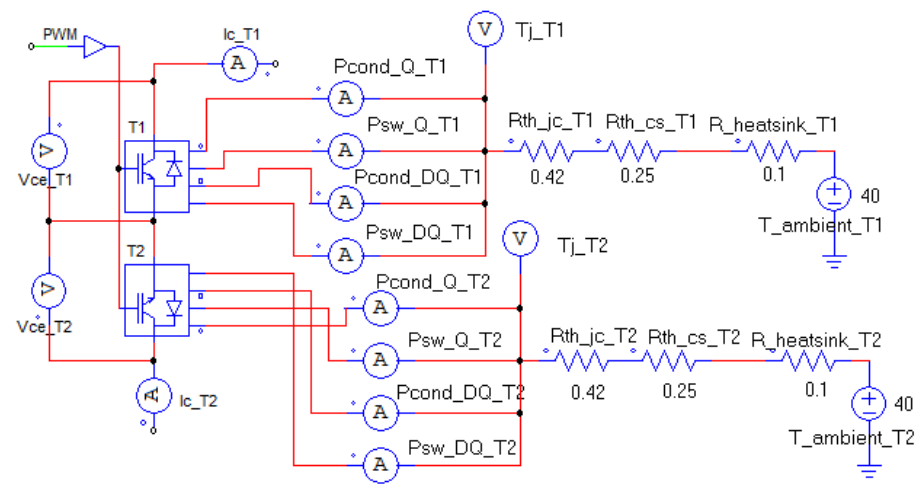

Fig.6: IGBT Configuration for conduction in both Cycles.

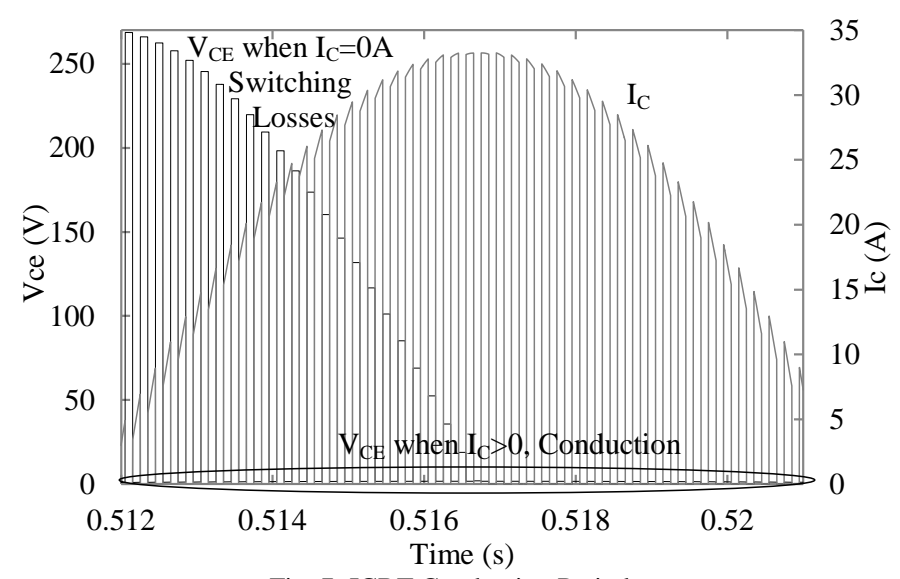

Fig. 7: IGBT Conduction Period.

As shown on Fig. 4, the collector current is best described as a half cycle (rectified) sinusoid signal. However, Fig. 7 clearly identifies the limits of integration. Hence, the average value given as:

$$
I_{C_{-} A V G}=D \frac{1}{T} \int_{T / 2}^{T} I_{C_{-} p e a k} \cos (\omega t) d t=D \frac{I_{C_{-} p e a k}}{\pi}
$$

In addition the saturation collector-emitter voltage $\mathrm{V}_{\text {CESAT }}$, is also described as a half cycle (rectified) sinusoid signals with the average value given as:

$$
\begin{gathered}
V_{C E S A T_{-} A V G}=D \frac{1}{T} \int_{T / 2}^{T} V_{\text {CESAT_peak }} \sin (\omega t) d t \\
V_{C E S A T_{-} A V G}=D \frac{V_{C E S A T} \text { peak }}{\pi}
\end{gathered}
$$

Hence, as shown on Fig. 8, the average conduction losses, $P_{\text {cond_AVG }}$, given $\mathrm{I}_{\mathrm{C} \_ \text {peak }}=33.2 \mathrm{~A}, \mathrm{~V}_{\mathrm{CESAT}}{ }_{\text {ppak }}=1.66 \mathrm{~V}$ and a switching frequency duty cycle, $\mathrm{D}$ of $50 \%$, are given by

$$
P_{\text {cond_AVG }}=\frac{I_{C \_ \text {peak }} V_{C E S A T \_p e a k}}{\pi} D
$$

Using (4) the conduction losses are calculated to $8.77 \mathrm{~W}$ and are also tabulated on table III.

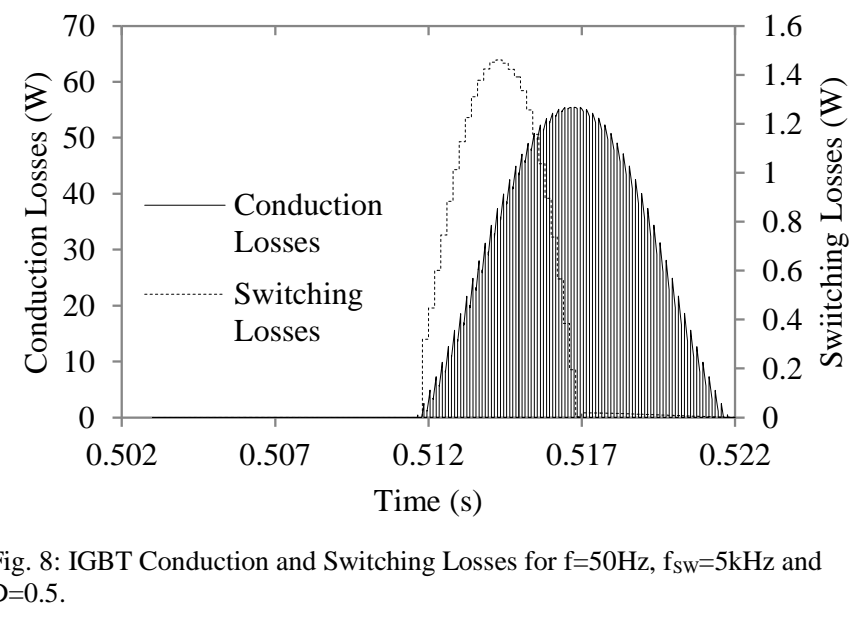

The switching losses are composed of two components; turning-on and turning-off losses. These losses take into account the time it takes for the current and voltage to change state from $\mathrm{ON}$ to $\mathrm{OFF}$ and vice-versa. Referring to Fig. 7, they are described as a quarter cycle (rectified) signals one is cosine the other sinwave with the average value given as:

$$
V_{C E_{-} A V G}=D \frac{1}{T} \int_{0}^{T / 4} V_{C E_{-} \text {peak }} \sin (\omega t) d t=D \frac{V_{C E_{-} p e a k}}{2 \pi}
$$

Hence, including the switching delays, $V_{\mathrm{CE}_{-} \text {peak }}$ is $269 \mathrm{~V}$ then the losses can be rewritten as:

$$
\begin{gathered}
P_{S W}=P_{S W_{-} O N}+P_{S W_{-} O F F} \\
P_{S W}=\frac{f_{S W D I_{C-} \text { peakV } V_{C E_{-} p e a k}}}{2 \pi}\left[t_{R I S E}+t_{F A L L}\right]
\end{gathered}
$$

Using (7) the switching losses are calculated to $0.213 \mathrm{~W}$ and are also tabulated on Table III. Worth noting, that the IGBT delays were adjusted for the rise in temperature. Based on the manufacturer datasheet when the junction temperature increases then the delay to turn on and rise times are not affected whereas the delay to turn-off and fall time is linear to 
the temperature change. Hence, for the IGBT used (IXGT40N60C2D1) for a temperature increase from $25^{\circ} \mathrm{C}$ to $46.4^{\circ} \mathrm{C}$ then the $t_{d(o f f)}$ increased from $90 \mathrm{~ns}$ to $98.4 \mathrm{~ns}$ and the $t_{f}$ increased from 32 to $40 \mathrm{~ns}$.

TABle III: Comparisson Theoretical (EQ.4 AND 7) AND SimUlated SWITCHING LOSSES

\begin{tabular}{|c|c|c|c|c|c|}
\hline \multicolumn{2}{|c|}{ Theory } & \multicolumn{2}{c|}{ PSIM Simulation } & \multicolumn{2}{c|}{ Difference } \\
\hline $\mathrm{P}_{\text {cond }}$ & $\mathrm{P}_{\mathrm{sw}}$ & $\mathrm{P}_{\text {cond }}$ & $\mathrm{P}_{\mathrm{sw}}$ & $\mathrm{P}_{\text {cond }}$ & $\mathrm{P}_{\mathrm{sw}}$ \\
\hline$(\mathrm{W})$ & $(\mathrm{W})$ & $(\mathrm{W})$ & $(\mathrm{W})$ & $(\mathrm{W})$ & $(\mathrm{W})$ \\
\hline 8.77 & 0.213 & 8.62 & 0.268 & 0.15 & 0.055 \\
\hline
\end{tabular}

Equations 7 to 10 show the methodology suggested in [1] where losses are the summation of discrete values. Where $V_{C E}$ and $I_{C}$ is the peak operating values, $T$ is the period of the switching frequency; $M$ is the number of switching instances in a power cycle. The results are tabulated on Table IV.

$$
\begin{aligned}
& E_{O N}=\sum_{n=1}^{M / 4}\left[t_{R I S E} \frac{1}{2} V_{C E} \sin (\omega . T . n) I_{C} \cos (\omega . T . n)\right] \\
& E_{O F F}=\sum_{n=1}^{M / 4}\left[t_{F A L L} \frac{1}{2} V_{C E} \sin (\omega . T . n) I_{C} \cos (\omega . T \cdot n)\right]
\end{aligned}
$$

For the on-State the lost power is given by

$$
P_{\text {LossesSS }}=\sum_{n=1}^{M / 2}\left[t_{O N} V_{C E O N} I_{C} \sin (\omega . T . n)\right]
$$

The total losses using (7) to (9) can be rewritten as:

$$
P_{\text {LOSSES }}=\left(P_{O F F}+P_{O N}\right) \cdot f_{S W}+P_{\text {LossesSS }}
$$

TABLE IV: COMPARISSON SUMMATION OF DiCRETE VALUES (EQ. 8 TO 11) AND SIMULATED SWITCHING LOSSES

\begin{tabular}{|c|c|c|c|c|c|}
\hline \multicolumn{2}{|c|}{ Theory } & \multicolumn{2}{c|}{ PSIM Simulation } & \multicolumn{2}{c|}{ Difference } \\
\hline $\mathrm{P}_{\text {cond }}$ & $\mathrm{P}_{\mathrm{sw}}$ & $\mathrm{P}_{\text {cond }}$ & $\mathrm{P}_{\mathrm{sw}}$ & $\mathrm{P}_{\text {cond }}$ & $\mathrm{P}_{\mathrm{sw}}$ \\
\hline$(\mathrm{W})$ & $(\mathrm{W})$ & $(\mathrm{W})$ & $(\mathrm{W})$ & $(\mathrm{W})$ & $(\mathrm{W})$ \\
\hline 8.77 & 0.224 & 8.62 & 0.268 & 0.15 & 0.044 \\
\hline
\end{tabular}

Comparison between the results tabulated on Tables III and IV shows that techniques, integration and summation of discrete values, are the same with only a small difference on switching losses of $0.009 \mathrm{~W}$. Another method as suggested in [24] is to calculate the switching losses is to normalize given the datasheet values. However, this method only works for the switching losses. Hence, expression (9) can be rewritten as:

$$
P_{S W}=\frac{f_{S W} D I_{C} V_{C E}}{2 \pi}\left[\frac{E_{O N}+E_{O F F}}{I_{C} V_{C E}}\right]_{\text {Datasheet }}
$$

Taken directly from the datasheet for IGBT IXGT40N60C2D1 [6], $\mathrm{I}_{\mathrm{C}}=30 \mathrm{~A}, \mathrm{~V}_{\mathrm{CE}}=400 \mathrm{~V}, \mathrm{~T}_{\mathrm{j}}=25^{\circ} \mathrm{C}, \mathrm{E}_{\mathrm{ON}}=$ $20 \mathrm{~mJ}$ and $\mathrm{E}_{\mathrm{OFF}}=30 \mathrm{~mJ}$ then $\mathrm{P}_{\mathrm{sw}}=0.296 \mathrm{~W}$.

TABLE V: COMPARISSON DATASHEET NORMALISATION (EQ.12) AND SIMULATED SWITCHING LOSSES

\begin{tabular}{|c|c|c|}
\hline Datasheet Normalization & PSIM Simulation & Difference \\
\hline $\mathrm{P}_{\mathrm{sw}}$ & $\mathrm{P}_{\mathrm{sw}}$ & $\mathrm{P}_{\mathrm{sw}}$ \\
\hline$(\mathrm{W})$ & $(\mathrm{W})$ & $(\mathrm{W})$ \\
\hline 0.296 & 0.268 & 0.028 \\
\hline
\end{tabular}

Comparison between the results tabulated on Tables III to V shows that the PSIM simulation is the average between the Theory and Normalization methods. Worth noting that a closer investigation of the PSIM user manual revealed that for IGBT a normalization factor is used, including only the effects of $\mathrm{V}_{\mathrm{CE}}$.

TABLE VI: TOTAL POWER LOSSES FOR THE 4 IGBT

\begin{tabular}{|c|c|c|}
\hline Datasheet Normalisation & PSIM Simulation & Theory \\
\hline $\mathrm{P}_{\text {cond }}+\mathrm{P}_{\mathrm{sw}}$ & $\mathrm{P}_{\text {cond }}+\mathrm{P}_{\mathrm{sw}}$ & $\mathrm{P}_{\text {cond }}+\mathrm{P}_{\mathrm{sw}}$ \\
\hline$(\mathrm{W})$ & $(\mathrm{W})$ & $(\mathrm{W})$ \\
\hline $4 \times(0.296+8.77)$ & $4 \times(8.62+0.268)$ & $4 \times(8.77+0.213)$ \\
\hline $4 \times 9.066$ & $4 \times 8.888$ & $4 \times 8.983$ \\
\hline 36.264 & 35.552 & 35.932 \\
\hline
\end{tabular}

Table VI represents the total power. Multiplication by 4 is justified because within a cycle of the switching frequency we have two switching OFF and two switching ON actions. Specifically for the half cycle of positive current where modes $\mathrm{A}$ and $\mathrm{B}$ are interchanged, Within one cycle of the switching frequency $\mathrm{A}$ is replaced by $\mathrm{B}$ and then $\mathrm{B}$ by $\mathrm{a}$. For each change of mode we have a transistor and a diode switching OFF and another transistor and a diode switching ON. ie from mode A to Mode B transistor T21and a diode D22 are switching OFF and transistorT11 and a diode D12 switching ON. This is repeated in the reverse order when mode $\mathrm{B}$ is replaced by $\mathrm{A}$.

\section{LOSSES ANALYSIS FOR THE COMPENSATION PERIOD}

During voltage sags the system compensates so that the output load voltage remains almost constant $\left(331.8 \mathrm{~V}_{\mathrm{pk}}=\right.$ $236.9 \mathrm{~V}_{\mathrm{RMS}}$, which is only $2.05 \%$ from its value before the disturbance). as shown on Fig.3 and 9. During the compensation the duty cycle of the switches D is set to 1 so only the branch with the capacitor conducts, only 2 IGBTs conduct; pair T1 and T12, Fig 4 (a). Therefore, the pair of T21 and T22 has zero conduction and switching losses. However, the pair experiences a sinusoidal collector-emitter voltage of $500 \mathrm{~V}$.

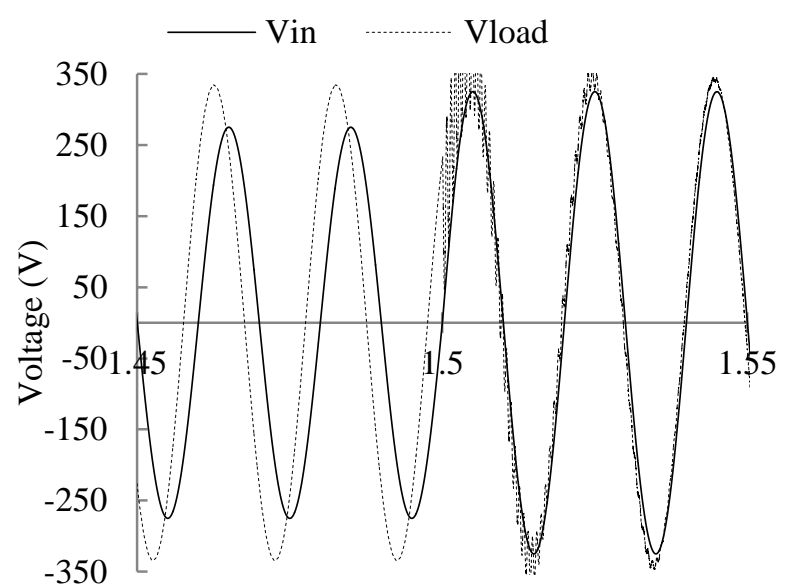

Time (s)

Fig.9: System Compensates for Voltage Sag.

During compensation the conducting pair of IGBT is kept $\mathrm{ON}$ with a duty cycle of $100 \%, \mathrm{D}=1$. The collector current, $\mathrm{I}_{\mathrm{C}}$

PRE-PRINT: S. Ioannou, CC Marouchos, M. Darwish and G. A. Putrus, "Efficiency Investigation of A Protection and Correction Solid State Device for LowVoltage Distribution Networks", 54 $4^{\text {th }}$ International Universities Power Engineering Conference (UPEC19), 978-1-7281-3349-2/19/\$31.00 @2019 IEEE, Romania, 2019. 
is $32.4 \mathrm{~A}$ and the collectro-emitter voltage, $\mathrm{V}_{\mathrm{CE}}$ is $1.65 \mathrm{~V}$. The simulated junction temperature is $52^{\circ} \mathrm{C}$. Figure 10 show the simulated IGBT conduction losses. Hence, since the conductions losses of Fig. 10 looks like a half wave rectified sinusoid then the methodology described using equations (1) to (7) was used. The theoretical results are tabulated on Table VII. The values are for a single IGBT.

TABLE VII: COMPARISSON THEORETICAL AND SIMULATED SWITCHING LOSSES

\begin{tabular}{|c|c|c|c|c|c|}
\hline \multicolumn{2}{|c|}{ Theory } & \multicolumn{2}{c|}{ PSIM Simulation } & \multicolumn{2}{c|}{ Difference } \\
\hline $\mathrm{P}_{\text {cond }}$ & $\mathrm{P}_{\mathrm{sw}}$ & $\mathrm{P}_{\text {cond }}$ & $\mathrm{P}_{\mathrm{sw}}$ & $\mathrm{P}_{\text {cond }}$ & $\mathrm{P}_{\mathrm{sw}}$ \\
\hline$(\mathrm{W})$ & $(\mathrm{W})$ & $(\mathrm{W})$ & $(\mathrm{W})$ & $(\mathrm{W})$ & $(\mathrm{W})$ \\
\hline 17.03 & $6.6 \mathrm{u}$ & 15.6 & $5.7 \mathrm{u}$ & 1.43 & $0.9 \mathrm{u}$ \\
\hline
\end{tabular}

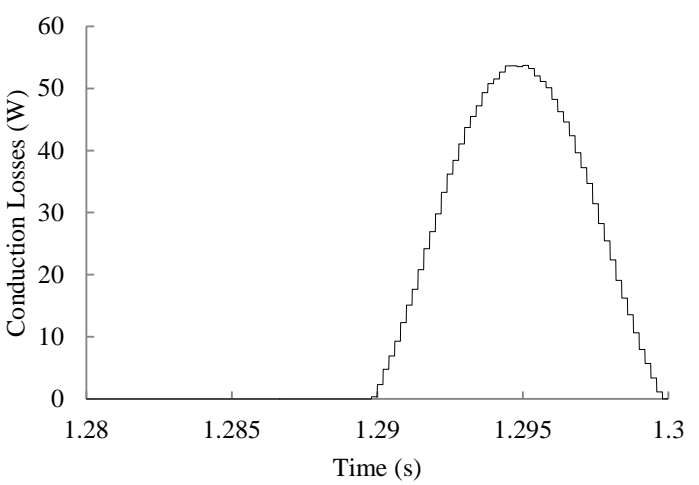

Fig. 10: Conduction Losses.

\section{DISCUSSION AND CONCLUSIONS}

A Fault Current Limiter is presented where the SC Circuit is employed to correct the P.F. and at the same time it is a solidstate fault current limiting and interrupting device (FCLID) for low voltage distribution networks. Control is achieved by setting the value of the duty cycle of the switches. The choice of values of $\mathrm{L}$ and $\mathrm{C}$ is critical. Optimisation is applied to correct the power factor to an acceptable value of 0.85 and keep the load voltage within acceptable limits. For a lagging power factor of 0.85 the Load voltage is always $5 \%$ above the supply.

Sag voltage correction is a new feature and it is taking advantage of the fact that the load voltage is increased with the insertion of the SC circuit. As it was shown, a compromise is achieved between power factor and acceptable increase of load voltage; improving the power factor to 0.85 and allowing an increase of the load voltage of only $5 \%$. As demonstrated it is possible to set the load voltage at about $12.5 \%$ higher with reference to the nominal voltage at the point of connection. Sag voltage correction is demonstrated where a sag of $15.3 \%$ is corrected back to $236.9 \mathrm{~V}_{\mathrm{RMS}}\left(331.8 \mathrm{~V}_{\mathrm{pk}}\right)$ which is only $2.05 \%$ from its value before the disturbance. This can either be tolerated or it is a useful feature in areas where the Grid voltage is low.

The losses of the switching semiconductors are investigated by employing the PSIM Thermal Module. This work shows that for switched capacitor circuits there is a $90^{\circ}$ phase shift between current and voltage. Comparison between the calculated and simulated losses shows a difference of $150 \mathrm{~mW}$ for conduction losses and $30 \mathrm{~mW}$ for switching losses.

Finally, since this process is repeated within one switching frequency cycle, the total switching losses within a cycle of the switching frequency is four times the losses of one transistor, totalling $36 \mathrm{~W}$.

\section{REFERENCES}

[1] F. Paterakis, CC Marouchos, G. A. Putrus and M. Darwish, "A solidstate fault current limiting and interrupting device (FCLID) with power factor correction", 53 ${ }^{\text {rd }}$ International Universities Power Engineering Conference (UPEC18), 2018.

[2] M. M. R. Ahmed, G. Putrus, Li Ran and R. Penlington, "Development of a prototype solid-state fault-current limiting and interrupting device for low- voltage distribution networks," in IEEE Transactions on Power Delivery, vol. 21, no. 4, pp. 1997-2005, Oct. 2006

[3] Radmanesh, S.H.Fathi, and G.B.Gharehpetian,"Novel high performance DC reactor type fault current limiter," Elect. Power Syst. Res., vol. 122, pp. 198-207, May 2015.

[4] H. Radmanesh, S. H. Fathi, G. B. Gharehpetian and A. Heidary, "A Novel Solid-State Fault Current-Limiting Circuit Breaker for Medium-Voltage Network Applications," in IEEE Transactions on Power Delivery, vol. 31, no. 1, pp. 236-244, Feb. 2016.

[5] A. Abramovitz and K. Ma Smedley, "Survey of Solid-State Fault Current Limiters," in IEEE Transactions on Power Electronics, vol. 27, no. 6, pp. 2770-2782, June 2012.

[6] Seyed Behzad Naderi, Mehdi Jafari, Mehrdad Tarafdar Hagh, Controllable resistive type fault current limiter (CR-FCL) with frequency and pulse duty-cycle, International Journal of Electrical Power \& Energy Systems, Volume 61, 2014, Pages 11-19, ISSN 0142-0615.

[7] C. Marouchos, M. K. Darwish and M. El-Habrouk, "Variable var compensator circuits," in IEE Proceedings - Electric Power Applications, vol. 153, no. 5, pp. 682-690, September 2006.

[8] C. C. Marouchos, M. Evdokimou and M. Darwish, "Application of the switched capacitor compensator in closed loop," 2014 49th International Universities Power Engineering Conference (UPEC), Cluj-Napoca, 2014, pp. $1-5$.

[9] C. C. Marouchos, G. A. Putrus, M. Darwish, F. Paterakis, "An investigation of the switched-capacitor circuit as a solid-state fault current limiting and interrupting device (FCLID) with power factor correction suitable for low-voltage distribution networks", UPEC2017 2017.

[10] S. Ioannou, E. K. Stefanakos and P. H. Wiley, "New MOV Failure Mode Identification Invention", IEEE Transactions on Consumer Electronics, Vol. 53, No. 3, pg.1068-1075, August 2007.

[11] T. G. Wilson, "The evolution of power electronics," IEEE Trans. ower Electron., vol. 15, no. 3, pp. 439-446, May 2000.

[12] B. K. Bose, "The past, present, and future of power electronics," IEEE Ind. Electron. Mag., vol. 3, no. 2, pp. 7-11, Jun. 2009.

[13] M. H. Rashid, "Power Electronics Handbook: Devices Circuits and Application, 3rd ed", Burlington, MA, USA: Elsevier, 2011.

[14] J. Bausch, "MOSFET vs IGBT", Discrete Power Transistors, Electronic Products, 2011, Online Posting: https://www.electronicproducts.com/Analog_Mixed_Signal ICs/Di screte Power Tra nsistors/MOSFET_vs_IGBT.aspx [15/5/2019].

[15] L. Mays, "FET vs. BJT vs. IGBT: What's the Right Choice for Your Power Stage Design", Technical Articles, All About Circuits, 2017, Online https://www.allaboutcircuits.com/technical-articles/fet- vs-bjt-vs-igbtwhats-the-right- choice-for-your- power-stage-design/ [May $14^{\text {th }}, 2019$ ].

[16] Ixus, "Datasheet -IXGT40N60C2D1", Online Posting: http://ixapps.ixys.com/datasheet/99052.pdf [April 19th, 2019].

[17] Mitsubishi, "Datasheet - CM1000HA-24H “, Online Posting: http://www.symmetron.ru/suppliers/mitsubishi/pwm_data/00000048.pdf [April 19th, 2019]. 
[18] Infineon, "Datasheet-F3L300R12PT4", OnlinePosting: https://www.infineon.com/dgdl/Infineon-F3L300R12PT4_B26-DSv02_00- en_de.pdf?fileId=db3a30433a747525013a87af3b9c6443 [April 19th, 2019].

[19] Infineon, "Datasheet - FF450R12KE4", Online Posting: https://www.infineon.com/dgdl/Infineon-FF450R12KE4_E-DS-v02_00EN.pdf?fileId=db3a304344d727a80144dfdce80e0c42 [ 19/4/2019].

[20] International Rectifiers, "Datasheet - IRGPS60B120KDP", Online Posting: https://www.infineon.com/dgdl/irgps60b120kdp.pdf?fileId=5546d462533 600a40153565a56b824a1 [April 19th, 2019].

[21] PowerSim Inc, "PSIM - User's Guide", 2017, Online Posting: https://powersimtech.com/products/psim/thermal/ [April 19th, 2019].

[22] A. S. Sedra and K. C. Smith, "MOS Power Transistors, pp1266-1277", Microelectronic Circuits 5th Edition, Oxford University Press, 2004.

[23] S. Ioannou, M. C. Argyrou, CC Marouchos and M. Darwish, "Efficiency Investigation of a Grid Connected PV System with Power Smoothing”, 54th International Universities Power Engineering Conference (UPEC19), 2019.

[24] N. Rao and D. Chamund, "Application Note - Calculating Power Losses in an IGBT Module", AN6156-1, LN31943, September 2014.

PRE-PRINT: S. Ioannou, CC Marouchos, M. Darwish and G. A. Putrus, "Efficiency Investigation of A Protection and Correction Solid State Device for LowVoltage Distribution Networks", 54 $4^{\text {th }}$ International Universities Power Engineering Conference (UPEC19), 978-1-7281-3349-2/19/\$31.00 @2019 IEEE, Romania, 2019. 